\title{
Apremilast, a novel phosphodiesterase 4 (PDE4) inhibitor, regulates inflammation through multiple cAMP downstream effectors
}

\author{
Miguel Perez-Aso ${ }^{1}$, M. Carmen Montesinos², Aránzazu Mediero ${ }^{1}$, Tuere Wilder ${ }^{1}$, Peter H. Schafer ${ }^{3}$ \\ and Bruce Cronstein ${ }^{1,4^{*}}$
}

\begin{abstract}
Introduction: This work was undertaken to delineate intracellular signaling pathways for the PDE4 inhibitor apremilast and to examine interactions between apremilast, methotrexate and adenosine $A_{2 A}$ receptors $\left(A_{2 A} R\right)$.

Methods: After apremilast and LPS incubation, intracellular CAMP, TNF-a, IL-10, IL-6 and IL-1a were measured in the Raw264.7 monocytic murine cell line. PKA, Epac1/2 (signaling intermediates for CAMP) and $A_{2 A} R$ knockdowns were performed by shRNA transfection and interactions with A2AR and A2BR, as well as with methotrexate were tested in vitro and in the murine air pouch model. Statistical differences were determined using one or two-way ANOVA or Student's t test. The alpha nominal level was set at 0.05 in all cases. A P value of $<0.05$ was considered significant.

Results: In vitro, apremilast increased intracellular CAMP and inhibited TNF-a release $\left(I C_{50}=104 \mathrm{nM}\right)$ and the specific $A_{2 A} R$-agonist CGS21680 $(1 \mu \mathrm{M})$ increased apremilast potency $\left(I_{50}=25 \mathrm{nM}\right)$. In this cell line, apremilast increased IL-10 production. PKA, Epac1 and Epac2 knockdowns prevented TNF-a inhibition and IL-10 stimulation by apremilast. In the murine air pouch model, both apremilast and MTX significantly inhibited leukocyte infiltration, while apremilast, but not MTX, significantly inhibited TNF-a release. The addition of MTX (1 mg/kg) to apremilast ( $5 \mathrm{mg} / \mathrm{kg}$ ) yielded no more inhibition of leukocyte infiltration or TNF-a release than with apremilast alone.

Conclusions: The immunoregulatory effects of apremilast appear to be mediated by CAMP through the downstream effectors PKA, Epac1, and Epac2. A2AR agonism potentiated TNF-a inhibition by apremilast, consistent with the CAMP-elevating effects of that receptor. Because the A2AR is also involved in the anti-inflammatory effects of MTX, the mechanism of action of both drugs involves CAMP-dependent pathways and is therefore partially overlapping in nature.
\end{abstract}

\section{Introduction}

Accumulating data since the 1950 s describe the properties of cyclic adenosine monophosphate (cAMP) as a pivotal second messenger in the regulation of inflammatory responses [1]. Cyclic AMP-specific phosphodiesterases (PDE), therefore, have emerged as a new target for the treatment of numerous inflammatory conditions (reviewed in [2]) as the anti-inflammatory properties of

\footnotetext{
* Correspondence: Bruce.Cronstein@nyumc.org

'Department of Medicine, New York University School of Medicine, 550 First Ave., New York, NY 10016, USA

${ }^{4}$ Division of Translational Medicine, Department of Medicine, New York University School of Medicine, 550 First Avenue, MSB251, New York, NY 10016, USA

Full list of author information is available at the end of the article
}

PDE inhibitors such as theophylline were being demonstrated during the 1970s [3]. cAMP-specific phosphiodiesterase type 4 (PDE4), a critical regulator of intracellular cAMP levels and compartmentalization [4], is mainly expressed within inflammatory cells [5]. Thus, inhibition of PDE4 suppresses the expression of TNF- $\alpha$, among other cytokines and chemokines, by $\mathrm{T}$ cells and monocytes [6-8]. PDE4 inhibitors are well-characterized pharmaceutical agents with a broad range of anti-inflammatory activity, as documented by numerous studies of low molecular-weight PDE4 inhibitors, such as rolipram [9].

The clinical development of a class of PDE4 inhibitor anti-inflammatory agents has been hindered by their side effects, principally nausea and emesis [10]. Indeed, despite their potential as anti-inflammatory agents, PDE4 
inhibitors have failed clinical trials due to the high prevalence of these and other side effects [11] such as headache, diarrhea, fatigue, dyspepsia, nasopharyngitis and gastroenteritis [12]. Thus, a major pharmaceutical research focus in the field of chronic inflammatory diseases was the development of novel PDE4 inhibitors with high therapeutic index [13]. The novel PDE4 inhibitor, apremilast, has a higher therapeutic index and was developed, introduced to the clinic $[14,15]$ and recently approved in the USA for the treatment of psoriatic arthritis (reviewed in [2]).

Unlike TNF- $\alpha$ inhibitors, which bind directly to TNF- $\alpha$, PDE4 inhibitors inhibit TNF- $\alpha$ production at the level of gene expression and do not completely suppress TNF- $\alpha$ levels in clinical settings. Rather, apremilast causes a broad, but not complete, inhibition of multiple proinflammatory mediators [16]. It is well-known that PDE4 inhibition promotes intracellular accumulation of cAMP, activation of Protein kinase A (PKA) and phosphorylation of the cAMP-response element binding protein (CREB), which, in turn, suppresses the transcription of numerous cytokines, such as TNF- $\alpha$, exerting therefore an overall anti-inflammatory effect [9]. However, the specific impact of apremilast on the expression of different cytokines and the role of other downstream effectors of cAMP, i.e., Exchange protein directly activated by cAMP (Epac) 1 and Epac2, in the mechanism of action of apremilast have not been previously addressed, nor has the interaction of apremilast with other systems that regulate cAMP levels, such as adenosine receptors, in particular with the $A_{2 A}$ adenosine receptor $\left(A_{2 A} R\right)$, which mediates many of the anti-inflammatory actions of methotrexate (MTX), the cornerstone treatment for rheumatoid arthritis [17]. Therefore, the aim of the present work was to analyze the downstream pathways triggered by apremilast and to test potential interactions of apremilast with MTX, and with the adenosine receptors in both in vitro and in vivo models of inflammation.

\section{Materials and methods \\ Air pouch model}

As previously described [17], male mice were given weekly intraperitoneal injections of either MTX $(1 \mathrm{mg} / \mathrm{Kg})$ or vehicle (phosphate-buffered saline; PBS) for 4 weeks. Air pouches were generated by subcutaneous injection of $3 \mathrm{ml}$ of sterile air and reinflated with $1.5 \mathrm{ml}$ of sterile air 2 days later. Vehicle $(0.5 \%$ carboxymethylcellulose and $0.25 \%$ Tween 80 ) or apremilast $(5 \mathrm{mg} / \mathrm{Kg}$ ) were orally dosed, with a syringe through a blunt-ended curved feeding tube, $24 \mathrm{~h}$ and $1 \mathrm{~h}$ before inflammation was induced on day 6 by injection of $1 \mathrm{ml}$ of $2 \%$ carrageenan suspension. Four hours later, mice were killed by $\mathrm{CO}_{2}$ narcosis, and exudates harvested with $2 \mathrm{ml}$ PBS. Leukocytes were counted in a hemocytometer chamber and concentrations of cytokines were measured by ELISA or by the Luminex platform as described below. All protocols followed internationally recognized guidelines and were approved by the New York University School of Medicine Institutional Animal Care and Use Committee (NYU SoM, IACUC, protocol number 130412).

\section{Histology}

Four-micron formalin-fixed, paraffin-embedded tissue sections were stained with $H \& E$ or with toluidine blue histochemicals by incubating sections in aqueous $0.01 \%$ toluidine blue for 5 minutes. Slides were washed in distilled water, quickly dehydrated through graded alcohols, cleared in xylene and mounted with synthetic permanent media [18].

Immunohistochemistry was performed on four-micron formalin-fixed, paraffin-embedded mouse skin tissue sections using rabbit anti-mouse CD3 (Ventana Medical Systems Tucson, AZ, USA) clone 2GV6, rat anti-mouse CD45R (BD Biosciences San Diego, CA, USA) clone RA3-6B2, rat anti-mouse CD68 (Abd Serotech, Raleigh, NC, USA) clone FA-11 and rat anti-mouse neutrophil (Abcam Cambridge, MA, USA) clone NIMP-R14. In brief, sections were deparaffinized in xylene (three changes), rehydrated through graded alcohols (three changes $100 \%$ ethanol, three changes $95 \%$ ethanol) and rinsed in distilled water. For $\mathrm{CD} 3$, heat-induced epitope retrieval was performed in a 1200-Watt microwave oven at $100 \%$ power in $10 \mathrm{mM}$ sodium citrate buffer, $\mathrm{pH} 6.0$ for 20 minutes. Sections were allowed to cool for 30 minutes and then rinsed in distilled water. Antibody incubations and detection were carried out at $37^{\circ} \mathrm{C}$ on a Discovery or NEXes instrument (Ventana Medical Systems Tucson, AZ, USA) platform using Ventana reagent buffer and detection kits unless otherwise noted. Endogenous peroxidase activity was blocked with hydrogen peroxide. Tissue sections for CD68 and anti-neutrophil were digested at $37{ }^{\circ} \mathrm{C}$ with alkaline endopeptidase for 12 and 6 minutes, respectively. All antibodies were diluted in Dulbecco's Phosphate-Buffered Saline (Life Technologies Grand Island, NY, USA). CD3 and CD45R were diluted 1:10 and incubated for $30 \mathrm{mi}-$ nutes. CD68 was diluted 1:10 and anti-neutrophil 1:1600 and incubated for $12 \mathrm{~h}$ at room temperature. CD3 was detected with biotinylated goat anti-rabbit (Vector Laboratories Burlingame, CA USA) diluted 1:200. CD45R and anti-neutrophil were detected with biotinylated goat antirat diluted 1:200 and CD68 was detected using biotinylated rabbit anti-rat, mouse absorbed (Vector Laboratories Burlingame, CA, USA) diluted 1:100. Secondary antibodies were incubated for 30 minutes at $37^{\circ} \mathrm{C}$. This was followed by the application of streptavidin-horseradish-peroxidase conjugate. The complex was visualized with 3,3 diaminobenzidene and enhanced with copper sulfate. Slides were washed in distilled water, counterstained with hematoxylin, 
dehydrated through graded alcohols, cleared in xylene and mounted with synthetic permanent media. Appropriate positive and negative controls were included with the study sections.

\section{cAMP measurements}

Intracellular cAMP was measured with the direct cAMP ELISA kit from Enzo Life sciences (Plymouth Meeting, PA, USA). Fifty-percent-confluent Raw 264.7 cells were starved for $24 \mathrm{~h}$ and stimulated at the indicated concentrations of apremilast for 30 minutes, and then with lipopolysaccharide (LPS) for 20 minutes, and cAMP was analyzed according to the manufacturer's protocol.

\section{TNF-a measurement}

Raw 264.7 cells $(100,000)$ were grown in 96-well plates. After $24 \mathrm{~h}$, cells were stimulated with vehicle (final concentration of $0.025 \%$ dimethyl sulfoxide (DMSO)) or with apremilast at the indicated concentrations. After 30 minutes cells were stimulated with LPS (L5886; Sigma, St Louis, MO, USA) $1 \mu \mathrm{g} / \mathrm{ml}$ for $4 \mathrm{~h}$. When studying CGS21680 (1063; Tocris Bioscience, Ellisville, MO, USA), SCH58261 (2270; Tocris Bioscience), ZM241385 (1036; Tocris Bioscience), BAY60-6583 (4472; Tocris Bioscience), or GS6201 (4727; Tocris Bioscience), the adenosine receptor ligands were added 15 minutes before apremilast. Methotrexate (Hospira Inc, Lake Forest, IL, USA) was added $24 \mathrm{~h}$ and $1 \mathrm{~h}$ before apremilast. Supernates were then collected and TNF- $\alpha$ levels were quantified with the Mouse TNF- $\alpha$ Quantikine ELISA Kit (MTA00B; R\&D systems; Minneapolis, MN, USA) following the manufacturer's instructions.

\section{IC50 calculation and statistics}

IC50 (EC50) calculations were made using non-linear regression, sigmoidal dose-response, constraining the top to $100 \%$ and bottom to $0 \%$, allowing variable slope, using GraphPad Prism v6.00.

\section{Western blotting}

Seventy-percent-confluent Raw 264.7 cells were starved for $24 \mathrm{~h}$ and stimulated with apremilast for 30 minutes and then with LPS for different time points $(n=4)$, Cells were lysed with radioimmunoprecipitation assay (RIPA) buffer and protein concentration was determined by bicinchoninic acid (BCA). Protein $(4 \mu \mathrm{g})$ was subjected to 7.5 or $10.0 \%$ SDS-PAGE and transferred to a nitrocellulose membrane. Nonspecific binding was blocked with TBS/Tween-20 0.05-3 \% BSA. Membranes where incubated overnight $\left(4{ }^{\circ} \mathrm{C}\right)$ with primary rabbit polyclonal anti-pCREB (Abcam, Cambridge, MA, USA), mouse monoclonal anti-CREB (Abcam), rabbit polyclonal anti-PDE4 (Abcam) and mouse monoclonal anti-Actin (1:1000 each). Membranes were incubated with goat anti-rabbit IRDye $800 \mathrm{CW} 1: 10000$ and goat anti-mouse IRDye 680 RD 1:10000 (Li-cor Biosciences) in the dark. Proteins were visualized by Li-cor Odyssey equipment, which detects near-infrared fluorescence. As each secondary antibody emits a signal in a different spectrum, reprobing with actin (to check that all lanes were loaded with the same amount of protein) was performed simultaneously with primary antibody incubation. Intensities of the respective band were quantitated by densitometric analysis using Image Studio 2.0.38 software (Li-cor Biosciences). Variations in band intensity were expressed as the percent of unstimulated controls, to minimize disparities among different experiments.

\section{Quantitative reverse transcription (RT)-PCR}

Total RNA was extracted and purified using the RNeasy Mini Kit (QIAGEN, Valencia, CA, USA) according to the manufacturer's protocol. Relative quantification of gene expression was performed using real-time RT-PCR on the Mx3005P Real-Time PCR System (Strategene, Agilent technologies Santa Clara, CA, USA) with SYBR Green (Agilent technologies, 600548, Santa Clara, CA, USA) according to the manufacturer's protocol. The following primers were used in real-time PCR amplification: Glyceraldehyde-3-phosphate dehydrogenase (GAPDH) forward: 5 -CTACACTGAGGACCAGGTTGTCT -3, reverse: 5- GGTCTGGGATGGAAATTGTG -3; Protein kinase A (PKA) forward: 5- CAGGAAAGCGCTCCAGA TAC -3, reverse: 5- AAGGGAAGGTTGGCGTTACT -3; Epac1 forward: 5- GTTGTCGACCCACAGGAAGT -3, reverse: 5- ACCCAGTACTGCAGCTCGTT -3; Epac2 forward: 5- GCATTGAGCAGGAGGACTTC -3, reverse: 5- AACGTGGGGTTCAATGAGAG -3; $\mathrm{A}_{2 \mathrm{~A}} \mathrm{R}$ forward: 5- AGCCAGGGGTTACATCTGTG -3, reverse: 5- TAC AGACAGCCTCGACATGTG -3. mRNA abundance was determined relative to that of GAPDH.

\section{Luminex assay}

Quantification of cytokines and chemokines was performed using Luminex x-MAP technology (Luminex Corp, Austen TX, USA). Tissue culture supernatants and mouse exudates were analyzed for expression of IL-1 $\alpha$, IL- 6 and IL-10 using a Milliplex multi-analyte magnetic bead panel from EMD Millipore (MCYTOMAG-70K, Billerica, MA, USA). Assays were performed according to the kit protocol using the appropriate matrix solution (culture media or PBS for supernatants and exudates, respectively). Data were collected on a Luminex 200 instrument and analyzed using Analyst 5.1 software (Millipore) with four-parameter logistic curve fitting. Samples were assayed in duplicate. All standard curves generated from the known reference cytokine concentrations supplied by the manufacturer had $R^{2}$ values calculated at or close to 1 and percent recovery 
between 80 and $120 \%$. Quality controls included with each kit performed as expected.

\section{Transfection protocol}

We have previously reported on the stably transduced PKA, Epac 1 and Epac 2 knockdown Raw 264.7 cells and shown that there was a marked reduction in the expression of these proteins [19]. Briefly, Raw 264.7 cells (15,000 cells/ml) were plated and $24 \mathrm{~h}$ later cells were incubated, in the presence of hexadimethrine bromide $(4 \mu \mathrm{g} / \mathrm{ml})$, with $10^{8}$ lentiviral transduction particles corresponding to mouse PKA catalytic alpha subunit shRNA (SHCLNV-NM_008854) EPAC1 (RAPGEF3, SHCLNV-NM_144850) or EPAC2 (RAPGEF4, SHCLNV-NM_019688) with puromycin selection marker for another $24 \mathrm{~h}$, to allow transfection. Media was then replaced with $\alpha M E M$ containing puromycin $(1 \mathrm{ug} / \mathrm{ml})$, changing the media every 3 days until selected clones formed. These clones were isolated and expanded until confluence. Scrambled shRNA (SHC002V) was used as control. Permanently silenced clones were kept in culture under puromycin selection.

\section{Statistical analysis}

Statistical differences were determined using one-way or two-way analysis of variance (ANOVA) or Student's $t$ test carried out using GraphPad software (v 6.00, GraphPad Software, Inc.) on a PC. The alpha nominal level was set at 0.05 in all cases. A $P$ value $<0.05$ was considered significant.

\section{Results}

\section{Apremilast and methotrexate independently prevent} inflammation in vitro and in the murine air pouch in vivo model of inflammation

Apremilast has previously been shown to inhibit TNF- $\alpha$ production from human rheumatoid synovial cells and this ameliorates arthritis in the experimental model of collagen-induced arthritis [20]. Interestingly, in the air pouch model, an in vivo model that mimics the synovial cavity, we have also demonstrated that the antiinflammatory actions of MTX, the cornerstone treatment for rheumatoid arthritis, are mediated in large part, by increasing adenosine levels [17], which, via activation of the $A_{2 A} R$, increase intracellular cAMP levels [21]. We therefore sought to study apremilast and MTX combined anti-inflammatory actions in both in vivo and in vitro models.

In vivo, an air pouch was formed on the dorsum of the mice (Fig. 1a), and the characteristic air pouch membrane was formed (A.M.; H\&E on Fig. 1b) [22] with a cell infiltrate comprised almost exclusively of neutrophils. Among cells forming the cellular infiltrate, we also found a small quantity of $\mathrm{CD}^{+} \mathrm{T}$ cells, but we did not detect any $\mathrm{B}$ cells, macrophages or mast cells, as analyzed by immunohistochemistry with B220 and CD68 markers, and by toludine blue stain, respectively.

Apremilast, orally administered (5 mg/Kg), significantly inhibited TNF- $\alpha$ production in the air pouch by $39 \%$ (61 $\pm 6 \%$ of vehicle, $P<0.001)$ and diminished (by $28 \%)$ the number of leukocytes present $(72 \pm 12 \%$ of vehicle, $P<0.05$; Fig. 2a). In agreement, immunohistologic analysis shows that neutrophil accumulation in the air pouch membrane was dramatically reduced by apremilast (Fig. 2b). We measured different mediators of inflammation with the Luminex multiplex platform and found that apremilast treatment did not significantly change the levels of IL- $1 \alpha$, IL-10 and IL- 6 in the air pouch exudates (Fig. 2c).

We next pretreated mice with low-dose MTX $(1 \mathrm{mg} / \mathrm{Kg}$, one dose per week for 4 weeks) prior to apremilast treatment, and studied the inflammation of the air pouch. As shown in Fig. 2d, both apremilast and MTX decreased leukocyte accumulation, and apremilast significantly reduced TNF- $\alpha$ levels. When administered together there was no additive reduction of either TNF- $\alpha$ or leukocyte accumulation in the air pouch. Similarly, no differences were found for the levels of IL-1 $\alpha$, IL- 6 and IL-10 treated with apremilast + MTX or apremilast alone (not shown). Because many, but not all of the actions of MTX, working through $\mathrm{A}_{2 \mathrm{~A}} \mathrm{R}$, were identical and not additive, our results and prior published data suggest that the actions of these agents in suppressing inflammation might be mediated by similar signaling pathways. Thus, we analyzed the intracellular pathways activated by apremilast in vitro.

\section{Apremilast increases intracellular cAMP and inhibits TNF- $a$ release by LPS in the mouse macrophage Raw 264.7 cell line}

Apremilast inhibits PDE4 with an $\mathrm{IC}_{50}$ of $74 \mathrm{nM}$ using $1 \mu \mathrm{M}$ cAMP as substrate [16]. Although apremilast is not selective for the different PDE4 isoforms (PDE4A4, PDE4B2, PDE4C2 and PDE4D3), as studied with recombinant enzymes, it is indeed PDE4-selective as it did not show significant inhibition of other PDE families at $10 \mu \mathrm{M}$ [16]. As shown in Fig. 3a, the Raw 264.7 cell line expressed several different isoforms of PDE4 and apremilast significantly increased intracellular cAMP, whether or not cells were challenged by LPS (Fig. 3b, two-way ANOVA analysis; apremilast vs control, $P<0.001$; apremilast plus LPS vs vehicle, not significant), which suggests that the apremilast-mediated cAMP increase is independent of macrophage activation. Consistent with the functional effects of the apremilast-induced increase in cAMP concentrations, apremilast promoted phosphorylation of CREB (Fig. 3c), in agreement with the hypothesis that apremilast activates the anti-inflammatory cAMP/ p-CREB pathway [23]. 


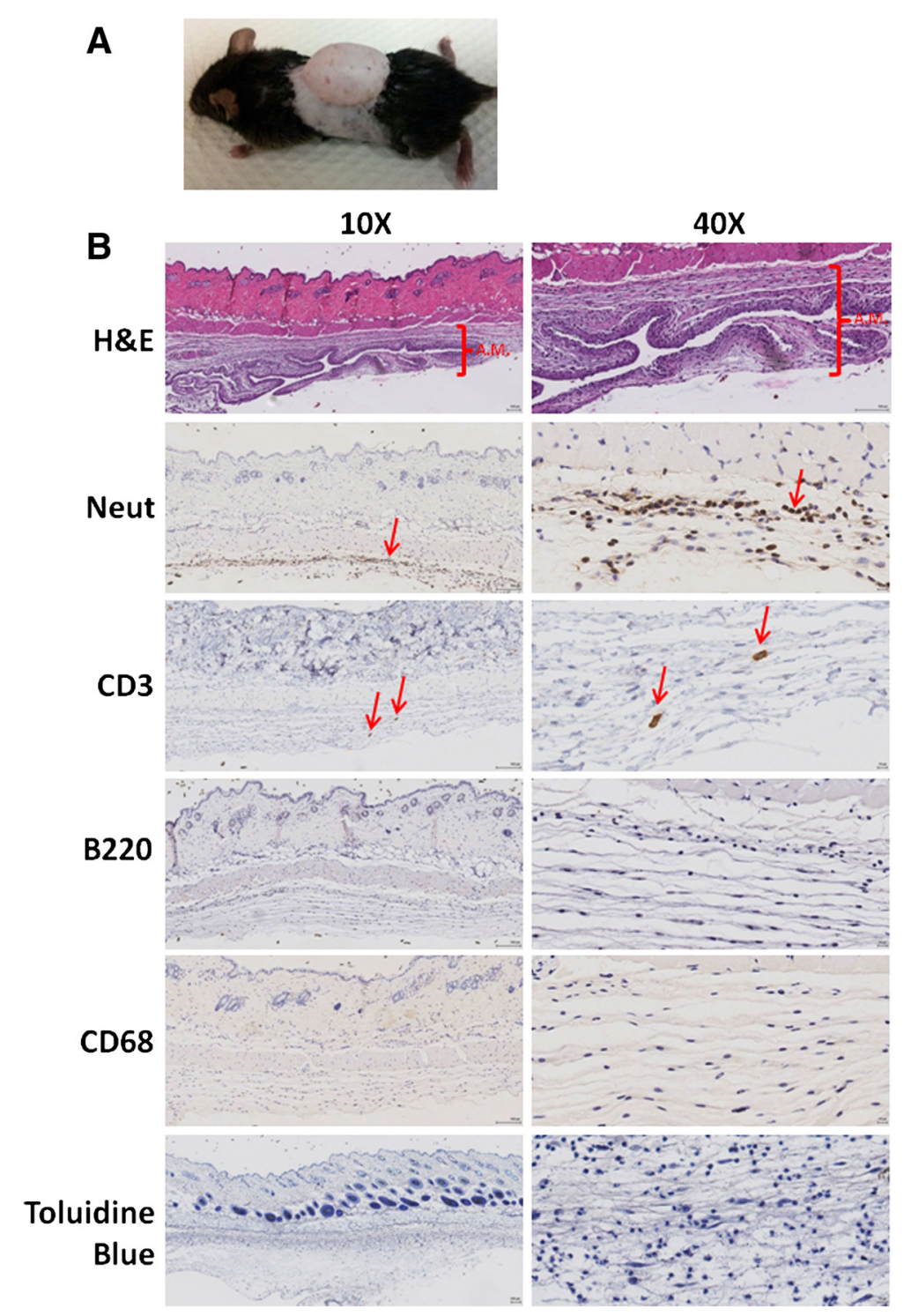

Fig. 1 Air pouch model of inflammation. a Inflammation in the air pouch was induced as described. $\mathbf{b}$ H\&E reveals the formation of the air pouch membrane (A.M.) and immunohistology staining with specific neutrophil (Neut), T cell (CD3), B cell (B220) and macrophage (CD68) markers, and the toluidine blue stain for mast cells was performed

As expected, LPS increased TNF- $\alpha$ release (from $1,345 \pm 273 \mathrm{pg} / \mathrm{ml}$ to $9,624 \pm 1,755 \mathrm{pg} / \mathrm{ml} ; P<0.01)$. A dose-inhibition curve was performed to analyze the impact of increasing concentrations of apremilast showing that apremilast inhibited TNF- $\alpha$ release by LPS with an $\mathrm{IC}_{50}$ of $104 \mathrm{nM}\left(\mathrm{pIC}_{50}=6.98 \pm 0.2\right.$; Fig. 3d), which almost exactly replicates previous reported TNF- $\alpha$ inhibition by apremilast on peripheral blood mononuclear cells (PBMCs) $\left(\mathrm{IC}_{50}=110 \mathrm{nM}\right)$ and which is similar to the potency of apremilast for PDE4 enzymatic inhibition $\left(\mathrm{IC}_{50}=74 \mathrm{nM}\right)$ [24]. These results are clearly consistent with the hypothesis that apremilast inhibits TNF- $\alpha$ by increasing intracellular cAMP levels.

\section{$A_{2 A} R$, but not $A_{2 B} R$, activation and apremilast exert additive TNF- $a$ inhibition}

Adenosine, a purine nucleoside generated by the dephosphorylation of adenine nucleotides, exerts potent antiinflammatory actions [21]. Indeed, adenosine inhibits TNF- $\alpha$, IL- 6 and IL-12 release and augments IL-10 production stimulated by LPS mostly through activation of the $A_{2 A} R$, a $G$ protein coupled receptor [25-27]. Moreover, there is evidence that the $A_{2 B} R$ exerts antiinflammatory actions as well, as it was found that $A_{2 B} R$ augments LPS-induced IL-10 production in the Raw 264.7 cell line [28]. As both the A2AR and the A2BR couple to Gs protein and increase intracellular cAMP production 


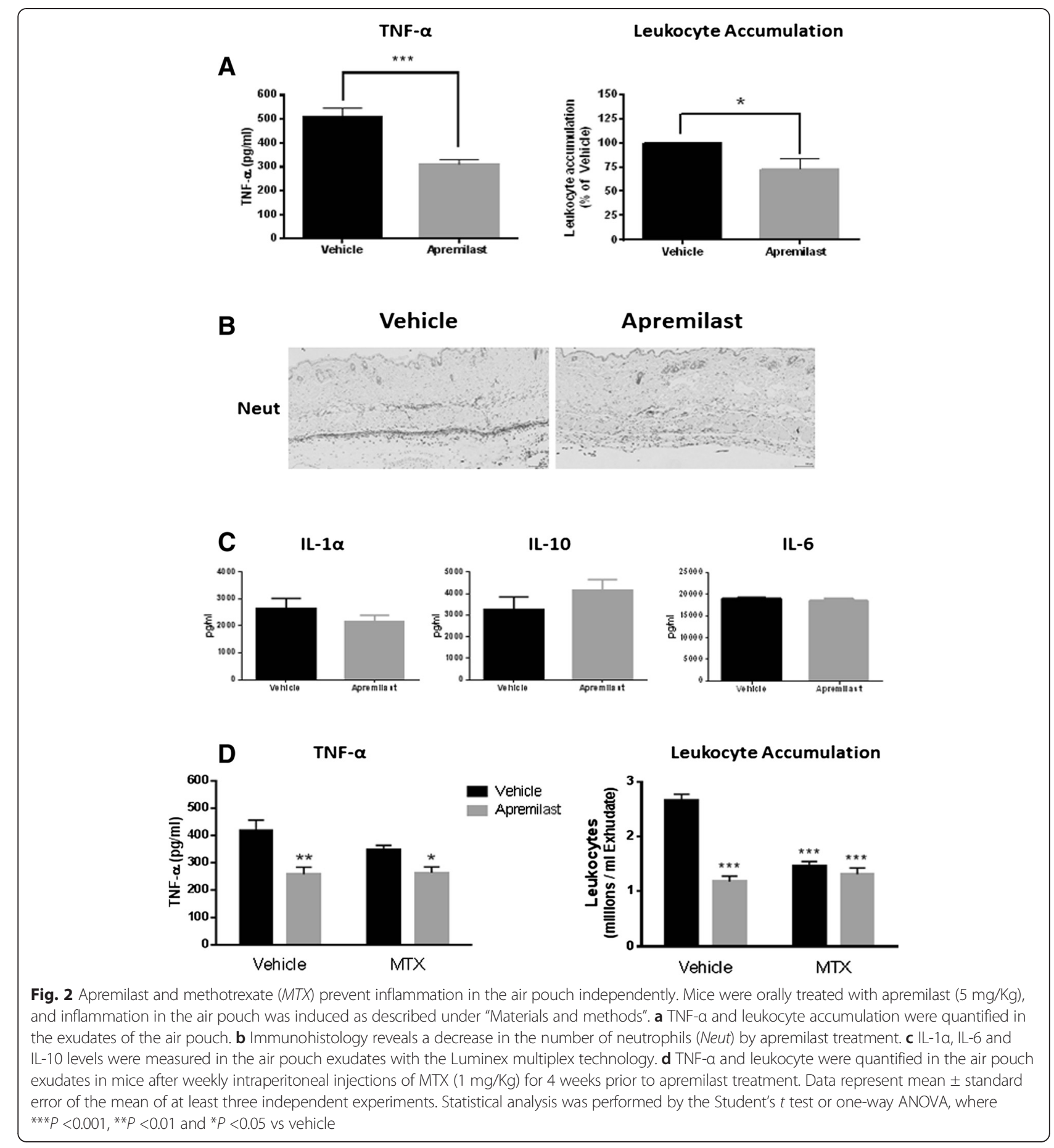

[21] we hypothesized that apremilast may enhance the actions of both $A_{2 A} R$ and $A_{2 B} R$. When the specific $A_{2 A} R$ agonist CGS21680 $(1 \mu \mathrm{M})$ was added to apremilast there was a significant reduction in the $\mathrm{IC}_{50}$ for apremilast inhibition of TNF- $\alpha$ release, from $104 \mathrm{nM}$ to $25 \mathrm{nM}\left(\mathrm{pIC}_{50}\right.$ of apremilast + vehicle vs $\mathrm{pIC}_{50}$ of apremilast + CGS21680 $1 \mu \mathrm{M}: P<0.0001$, Student's $t$ test; Fig. 4a), indicating that $\mathrm{A}_{2 \mathrm{~A}} \mathrm{R}$ activation and apremilast were additive. However, co-stimulation with CGS21680 and apremilast did not further increase intracellular cAMP levels when compared to either agent alone, though there was some additivity noted at the lower concentrations of CGS21680 and apremilast (Additional file 1: Figure S1). Interestingly, when the impact of two different $\mathrm{A}_{2 \mathrm{~A}} \mathrm{R}$ antagonists (SCH58261 $1 \mu \mathrm{M}$ and ZM241385 $1 \mu \mathrm{M}$ ) on the TNF- $\alpha$ inhibition by apremilast was studied, no significant changes were found 


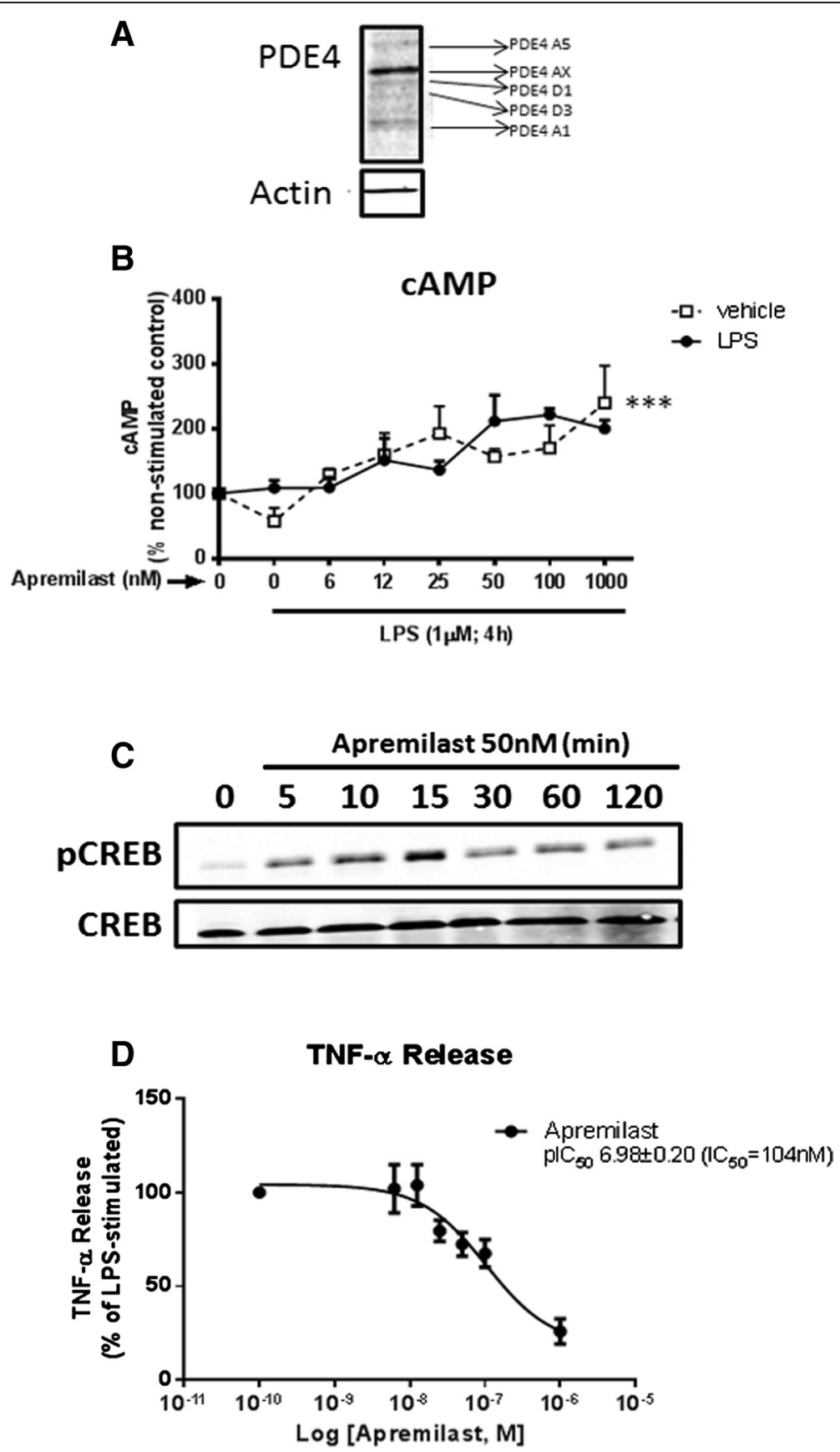

Fig. 3 Apremilast inhibits lipopolysaccharide (LPS)-induced TNF-a release via cyclic adenosine monophosphalphate (CAMP). a Western blot of PDE4 was performed in the Raw 264.7 cell line. b Raw 264.7 cells were incubated with increasing concentrations of apremilast 30 minutes before incubation with or without LPS 1 MM during 20 minutes. Intracellular cAMP levels were then measured as described under "Materials and methods". c Western blot of $p$-CAMP responsive element binding protein ( $p$-CREB) and CREB shows that apremilast promotes CREB phosphorylation after incubation with LPS $1 \mu \mathrm{g} / \mathrm{ml}$ for 30 minutes. d Cumulative concentration response curves to apremilast $(6 \mathrm{nM}-1 \mu \mathrm{M})$ were performed in the Raw 264.7 cells 30 minutes before incubation with LPS $1 \mu \mathrm{M}$ during $4 \mathrm{~h}$. IC $\mathrm{C}_{50}$ values were determined as described under "Materials and methods". Data represent means \pm standard error of the mean of four independent experiments. Statistical analysis was performed by two-way ANOVA: apremilast ${ }^{* * *} P<0.001$, LPS: not significant. PDE4 phosphodiesterase 4,

(Fig. 4b), indicating that $A_{2 A} R$ blockade alone does not prevent apremilast inhibition of TNF- $\alpha$ despite the interaction between $\mathrm{A}_{2 \mathrm{~A}} \mathrm{R}$ activation and PDE4 inhibition.
Further corroboration that diminished $\mathrm{A}_{2 \mathrm{~A}} \mathrm{R}$ activity does not interfere with apremilast, is provided by the finding that when the $A_{2 \mathrm{~A}} \mathrm{R}$ was knocked down $\left(\mathrm{A}_{2 \mathrm{~A}} \mathrm{R}\right.$ shRNA: $54 \%$ 

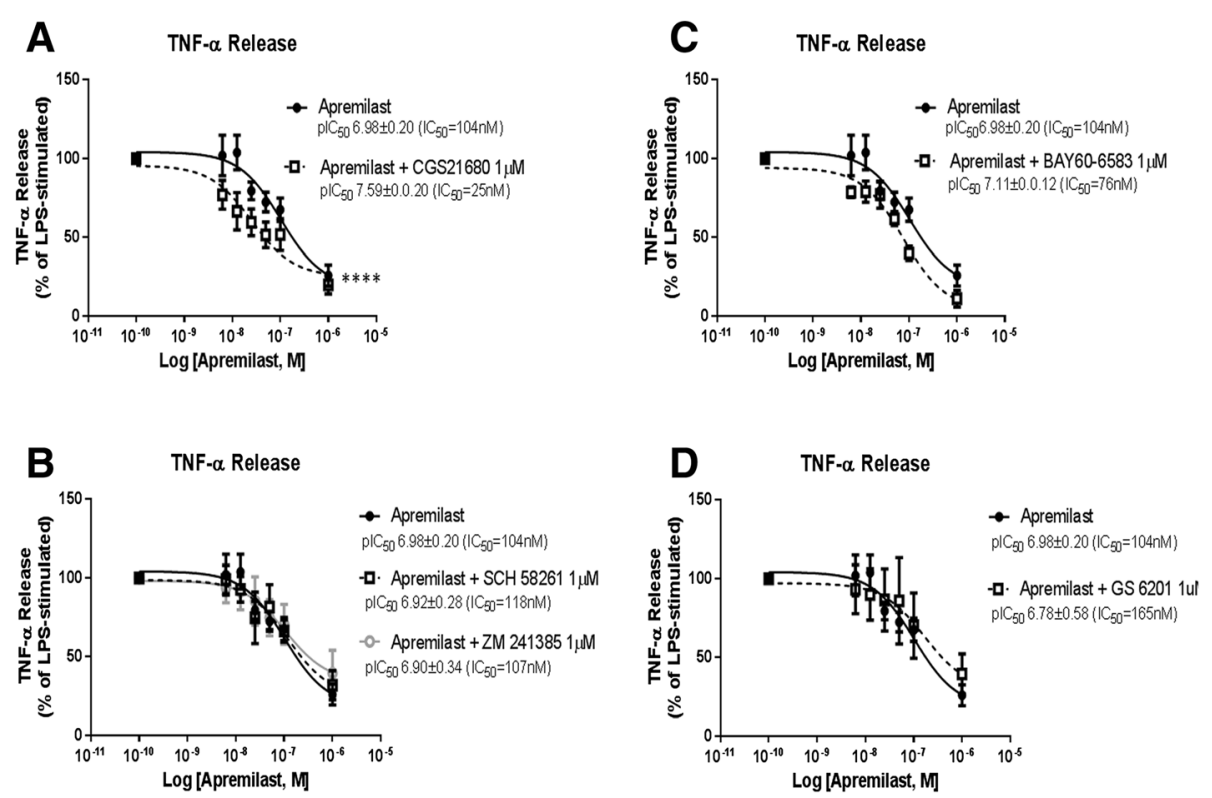

Fig. 4 Combined effects adenosine $A_{2} A$ receptor $\left(A_{2 A} R\right)$, adenosine $A_{B} A$ receptor $\left(A_{2 B} R\right)$ and apremilast on inhibition of TNF-a release. Cumulative concentration response curves to apremilast $(6 \mathrm{nM}-1 \mu \mathrm{M})$ were performed in the Raw 264.7 cells 30 minutes before incubation with lipolysaccharide (LPS) $1 \mu \mathrm{M}$ during $4 \mathrm{~h}$. We added CGS21680 $1 \mu \mathrm{M}$ (a), SCH $582611 \mu \mathrm{M}$ or ZM $2413851 \mu \mathrm{M}$ (b), BAY60-6583 $1 \mu \mathrm{M}$ (c) or GS $62011 \mu \mathrm{M}$ (d) 15 minutes before apremilast. $I C_{50}$ values were determined as described under "Materials and methods". Data represent means \pm standard error of the mean of three to four independent experiments

expression compared to non-target shRNA) apremilast inhibited TNF- $\alpha$ production by LPS to a similar extent (non-target shRNA: $81 \pm 2 \%$ TNF- $\alpha$ inhibition vs $\mathrm{A}_{2 \mathrm{~A}} \mathrm{R}$ shRNA: $66 \pm 9 \%, P<0.05)$.

Next, we studied the impact of a specific $A_{2 B} R$ agonist (BAY60-6583 $1 \mu \mathrm{M}$ ) and a specific $\mathrm{A}_{2} \mathrm{BR}$ antagonist (GS $62011 \mu \mathrm{M})$ on apremilast-mediated inhibition of TNF- $\alpha$ release. Neither the specific $A_{2 B} R$ agonist nor the antagonist significantly affected apremilast-mediated inhibition of TNF- $\alpha$ release (Fig. 4c, c), indicating that the $\mathrm{A}_{2 \mathrm{~B}} \mathrm{R}$ does not modulate the anti-inflammatory effects of apremilast.

Previous work has shown that MTX exerts its antiinflammatory actions by increasing adenosine activation of the $A_{2 A} R$ [25-27], so we analyzed the impact of MTX on TNF- $\alpha$ release by LPS. As expected from previous reports studying the anti-inflammatory mechanism of MTX in vitro [29], MTX inhibited the TNF- $\alpha$ increase upon LPS challenge by as much as $77 \pm 15 \%$ (MTX $25 \mathrm{nM} ; \mathrm{n}=3$ ) in the Raw 264.7 cell line (Fig. 5). However, the combination of MTX + apremilast at a wide range of concentrations of both agents (apremilast 0.1, 50.0 and $1000.0 \mathrm{nM}$; MTX 0.12, 0.25, 0.5, 1.0 and $10.0 \mu \mathrm{M}$ ) did not differ from apremilast alone with respect to inhibition of TNF- $\alpha$ (not shown), suggesting that the mechanisms of both MTX and apremilast regulation of TNF-alpha are overlapping.
Role of PKA and Epac1/2 in the anti-inflammatory actions of apremilast

In eukaryotic cells, the effects of cAMP are mainly mediated by two ubiquitously expressed intracellular cAMPregulated signaling proteins, PKA and the Exchange protein directly activated by cAMP/cAMP-regulated guanine nucleotide exchange factors (Epac1/2) [30], and by the cyclic nucleotide-gated ion channels [31]. We next examined the

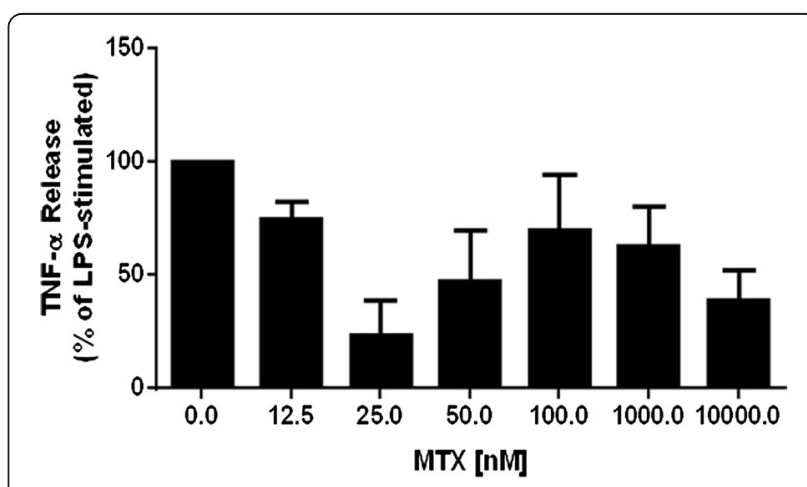

Fig. 5 Methotrexate (MTX) inhibits TNF-a release upon lipopolysaccharide (LPS) challenge. Raw 264.7 cells were incubated with increasing concentrations of MTX $24.0 \mathrm{~h}$ and $1.5 \mathrm{~h}$ before incubation without LPS $1 \mu \mathrm{M}$ during $4 \mathrm{~h}$. TNF-a levels were then measured as described under "Materials and methods". Data represent means \pm standard error of the mean of four independent experiments 
role of PKA and Epac1/2 in the anti-inflammatory effects mediated by PDE4 inhibition by apremilast.

We have previously shown that knocking down Epac1, Epac2 or PKA in the RAW264.7 cell line by cellular transduction with lentiviruses that express selective shRNA yields more selective information about the roles of Epac1, Epac2 or PKA in regulating cellular functions than their respective pharmacological inhibitors BFA [19] or the PKA inhibitor TTYADFIASGRTGRRNAIHD
[32]. We confirmed that these previously permanently transduced cells expressed less messaging for the target proteins and observed a specific decrease of $61 \%$, $77 \%$ and $60 \%$, respectively, for the PKA, Epac1 and Epac2 knockdown cells (Fig. 6a). In agreement, in the Raw 264.7 cell line, protein levels were dramatically decreased with the specific shRNAs (previously reported in [19] and in Additional file 2: Figure S2). In non-target shRNAtransfected cells, LPS increased TNF- $\alpha$ from $442.6 \pm 57.2$

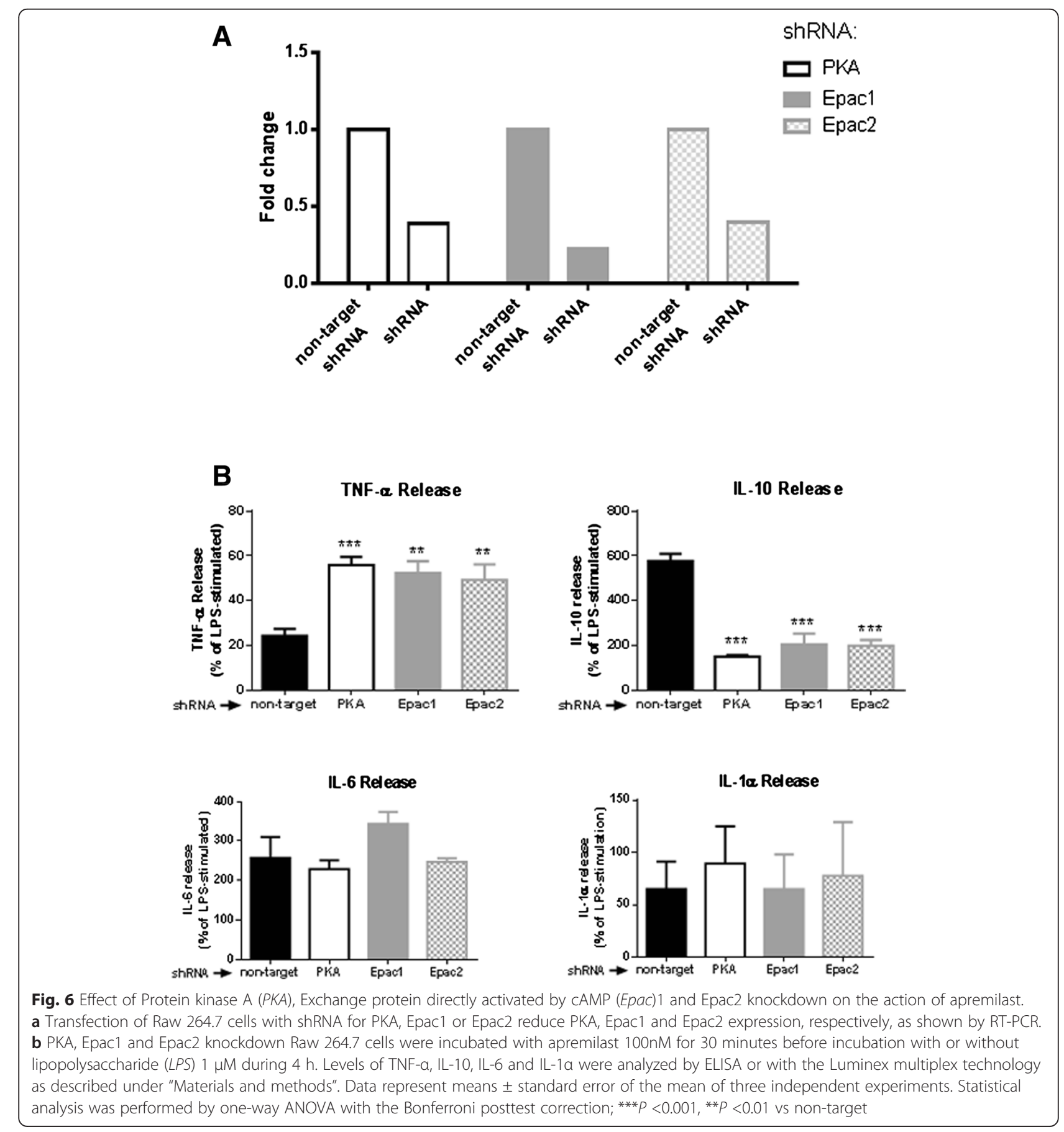


to $9731.6 \pm 2500.4 \mathrm{pg} / \mathrm{ml}(P<0.05)$ and apremilast treatment $(100 \mathrm{nM})$ inhibited TNF- $\alpha$ production by $76 \pm 3 \%$ (Fig. 6b), whereas knockdown of PKA, Epac1 and Epac2 reduced apremilast-mediated inhibition to $44 \pm 4 \%, 48 \pm 5 \%$ and $51 \pm 7 \%$ inhibition, respectively. These results suggest that cAMP-mediated inhibition of TNF- $\alpha$ production is mediated via PKA and Epac1/2 activation.

To further study the anti-inflammatory effects of apremilast we analyzed the effect of apremilast on cytokine release with the Luminex multiplex platform. Among cytokines increased by LPS (IL-10, IL- 6 and IL- $1 \alpha$ ), in non-target shRNA transfected cells apremilast further increased IL-10 (from $32 \pm 7$ to $181 \pm 33 \mathrm{pg} / \mathrm{ml}, P<0.05$ ). Apremilast showed a trend to increase IL- 6 in this murine cell line (from $811 \pm 416$ to $1,986 \pm 881 \mathrm{pg} / \mathrm{ml}, P<0.05$ ) and modestly diminished the LPS-mediated increase of IL- $1 \alpha$ (from $149 \pm 26$ to $97 \pm 35 \mathrm{pg} / \mathrm{ml}, P<0.05$ ). Interestingly, all three knockdowns for PKA, Epac1 and Epac2, prevented the apremilast-mediated increase of IL-10, but knockdown of these signaling molecules did not affect apremilast-mediated regulation of IL- 6 and IL- $1 \alpha$ levels (Fig. 6b, lower panels).

\section{Discussion}

PDE4 is the predominant cAMP-selective phosphodiesterase regulating the function of inflammatory cells [5] and selective PDE4 inhibitors have therefore generated great interest for the treatment of immune diseases, including inflammatory arthritis. Unfortunately most PDE4 inhibitors, such as rolipram, induce a variety of side effects, including nausea and emesis, because PDE4 is also highly expressed in the central nervous system [10]. As a consequence, early clinical studies with PDE4 inhibitors failed to demonstrate benefit due to the high incidence of these adverse effects [11].

Apremilast was discovered through evaluation of substitutions on a chemical scaffold, to optimize the structure-activity relationship of a particular series of PDE4 inhibitors $[14,15]$. The orally available PDE4 inhibitor inhibits spontaneous TNF- $\alpha$ production from human synovial membrane cultures and reduces the severity of disease in murine models of arthritis with similar efficacy to rolipram, but without any significant adverse effects [20]. Moreover, apremilast has been welltolerated in clinical trials, with a favorable benefit to risk profile [33, 34] and has recently been approved for the therapy of psoriatic arthritis.

In the air pouch model of inflammation in vivo, which mimics the synovial cavity in rheumatoid arthritis, we found an inflammatory exudate composed primarily of neutrophils with a small number of $\mathrm{T}$ cells (Fig. 1). Apremilast dramatically decreased the accumulation of neutrophils and inhibited TNF- $\alpha$ and IL- $1 \alpha$ production, while at the same time increasing the levels of the anti- inflammatory cytokine IL-10 (Fig. 2), further corroborating the pleiotropic anti-inflammatory actions of apremilast.

Apremilast is a well-described inhibitor of PDE4 [14], as measured on PDE4 and recombinant PDE4 isolated from cells $[14,16,35]$. The present work shows that apremilast increases intracellular cAMP in cell systems, consistent with PDE4 inhibition and previous data [15]. We found that apremilast promoted a significant increase of cytosolic cAMP in the Raw 264.7 cell line independently of LPS stimulation (Fig. 3b). Moreover, the potency of TNF- $\alpha$ inhibition by apremilast in these cells $\left(\mathrm{IC}_{50} 104 \mathrm{nM}\right)$ was nearly identical to that for its reported inhibition of PDE4 activity $\left(\mathrm{IC}_{50} 74 \mathrm{nM}\right)$ and TNF- $\alpha$ inhibition in peripheral blood mononuclear cells $\left(\mathrm{IC}_{50}=110 \mathrm{nM},[16]\right)$. As expected, these findings indicate that PDE4 inhibition by apremilast suppresses TNF- $\alpha$ production by increasing cAMP.

Interestingly, the anti-inflammatory action of MTX, the cornerstone drug for the treatment of rheumatoid arthritis and other inflammatory diseases [36], depends on the extracellular conversion of adenine nucleotides to adenosine [17]. Adenosine was described as an antiinflammatory agent nearly 30 years ago [21]. By binding the $\mathrm{A}_{2 \mathrm{~A}} \mathrm{R}$, which signals almost exclusively by increasing intracellular cAMP levels [37], adenosine has been shown to inhibit TNF- $\alpha$, IL- 6 and IL-12 release, while it augments IL-10 production induced by LPS [25-27]. We hypothesized that apremilast and $\mathrm{A}_{2 \mathrm{~A}} \mathrm{R}$ activation could interact at the cAMP level. Therefore, we investigated the impact of stimulation or blockade of the $\mathrm{A}_{2 \mathrm{~A}} \mathrm{R}$ on the apremilastmediated inhibition of TNF- $\alpha$ production, finding that the $\mathrm{A}_{2 \mathrm{~A}} \mathrm{R}$-specific agonist CGS21680 increases the potency of apremilast from an $\mathrm{IC}_{50}$ of $104 \mathrm{nM}$ to $25 \mathrm{nM}$ (Fig. 4a). However, in the presence of apremilast, CGS21680 did not further increase the levels of cAMP (Additional file 1: Figure S1) and $\mathrm{A}_{2 \mathrm{~A}} \mathrm{R}$ pharmacological blockade (Fig. 4b) did not further alter apremilast inhibition of TNF- $\alpha$. This apparent discrepancy might be explained by an insufficient amount of endogenous adenosine production in the cellular system. Similarly, despite its potential link to enhanced cAMP levels, $A_{2 B} R$ activation or blockade did not affect TNF- $\alpha$ inhibition by apremilast (Fig. 4c, d). Moreover, we were surprised to find that apremilast showed a trend to increase IL-6 production in vitro, although we did not detect any increase in vivo. In contrast, stimulation of $\mathrm{A}_{2 \mathrm{~A}} \mathrm{R}$ diminishes IL-6 production [21]. Interestingly, treatment with MTX diminishes circulating IL-6 levels in patients $[38,39]$ although the effect of the drug alone on IL-6 production in vitro is equivocal [40-42]. In patients with psoriatic arthritis, apremilast has been shown to reduce plasma levels of TNF- $\alpha$, IL-6, and other pro-inflammatory cytokines and chemokines [43].

The $\mathrm{A}_{2 \mathrm{~A}} \mathrm{R}$ is the only Gs-coupled adenosine receptor subtype that has not been reported to also couple to the 
Gq-protein [37] and thus, it signals almost exclusively by increasing cAMP levels. The findings reported here suggest that apremilast and $\mathrm{A}_{2 \mathrm{~A}} \mathrm{R}$ activation most likely interact by either transient cAMP signals and/or by compartmentalized cAMP increases, as previously found for prostaglandin E1 (PGE1), which triggers transient increases in the cAMP concentration near the plasma membrane, but not in total intracellular cAMP levels [44]. Indeed, recent studies indicate that there are distinct cAMP-signaling microdomains controlled by specific PDEs, which can differentially regulate independent processes controlled by cAMP [45-47], so this same signaling molecule can have opposing effects within the same cell due to a compartmentalized mechanism. On the other hand, although MTX prevents TNF- $\alpha$ release in vitro (Fig. 5) and inflammation in the air pouch via adenosine release [17], we did not detect additive effects of apremilast + MTX either in vitro (Fig. 5) or in vivo (Fig. 2d), which is in agreement with the finding that no additional benefit or risk is associated with combination of apremilast and methotrexate therapy [48]. Indeed, in a phase 3 study of apremilast demonstrating its efficacy and safety in patients with psoriatic arthritis, the majority of patients included in the trial were on concomitant MTX therapy at baseline [49]. In order to rule out interactions between apremilast and MTX, we tested a wide range of concentrations of both agents in a variety of combinations (apremilast 0.1, 50.0 and $1000.0 \mathrm{nM}$; MTX $0.12,0.25,0.5,1.0$ and $10.0 \mu \mathrm{M}$ ), finding a lack of interaction (data not shown), which may result from the variability of enhanced adenosine release in vitro leading to greater variability in the inhibition due to MTX.

Targeting PDE4 has enormous clinical potential due to its mechanism of action, which leads to increased intracellular cAMP levels in many different inflammatory cells, decreasing $\mathrm{T}$ cell and monocyte-derived cytokines such as TNF- $\alpha$ [6-8]. From studies using the PDE4 inhibitors roflumilast and rolipram, it is known that PDE4 inhibition leads to decreased TNF- $\alpha$ gene expression by a cAMP, PKA and NF-KB-dependent mechanism [9, 24]. Similarly, increased expression of the anti-inflammatory cytokine IL-10 is enhanced by PDE4 inhibitors in a PKA-dependent manner [50]. However, the discovery of the exchange protein directly activated by cAMP (Epac) suggested that the cAMP-mediated signaling mechanism is much more complex [30], so that cAMP exerts its effects not only via PKA activation, but also via Epac [51]. In particular, it has been suggested that many antiinflammatory effects of cAMP are mediated via the PKA pathway, while there are no major anti-inflammatory actions attributed to Epac [52, 53]. Moreover, prior studies have yielded results that support the suggestion that Epac activation following PDE4 inhibitor-mediated cAMP increases has pro-inflammatory effects and that addition of an Epac inhibitor to the PDE4 inhibitor treatment may lead to greater anti-inflammatory efficacy [53]. Although our studies demonstrate that the effects of apremilast on TNF $\alpha$ secretion are mediated by both PKA and Epac1/2 activation (Fig. 6b) it is likely that the different inflammatory stimuli used in the prior and current studies may account for this apparent discrepancy, LPS stimulation (present work) vs no stimulus ([53]).

These studies were carried out using a murine model of synovial inflammation, the air pouch model, and using murine macrophage cell lines. Both of these model systems reflect inflammatory events as they occur in patients, although neither of them are a perfect model. In the air pouch model inflammation is induced by the injection of carrageenan into an artificially created pouch that resembles the synovium, but the lining cells, while likely mesothelial in origin, are not synoviocytes and the inflammatory stimulus is not physiological. Similarly, the Raw 264.7 cells used here are derived from murine macrophages but there are likely other mutations in these cells that have rendered them immortal and which may exert some effect on the response to drugs or inflammatory stimuli. Nonetheless, these model systems permit a detailed study of the inflammatory milieu and support molecular probes of inflammatory signaling that are not possible in inflamed human synovium or primary human cells.

\section{Conclusions}

In summary, we report here that the novel PDE4 inhibitor apremilast is a potent inhibitor of inflammation via cAMP, PKA, and Epac1/2, and that interactions with the A2AR are likely due to compartmentalization of cAMP, rather than total cAMP changes. In an in vivo model that mimics the synovial cavity, apremilast exerts a potent anti-inflammatory action, which was not affected by MTX in this model. These results may help to explain the cAMP-dependent mechanism of action of apremilast as currently labeled for use in the treatment of psoriatic arthritis.

\section{Additional files}

\footnotetext{
Additional file 1: Figure S1. Adenosine $A 2 A$ receptor $\left(A_{2 A} R\right)$ activation and apremilast do not additively increase responsive element binding protein (CAMP). Raw 264.7 cells were incubated with cumulative concentrations of apremilast ( $6 \mathrm{nM}$ to $1 \mu \mathrm{M})$, apremilast + CGS21680 $1 \mu \mathrm{M}$ 15 minutes before apremilast, or cumulative concentrations of CGS21680 alone $(6 \mathrm{nM}$ to $1 \mu \mathrm{M})$, followed by treatment with lipopolysaccharide (LPS) $1 \mu \mathrm{M}$ for 20 minutes. Then, intracellular cAMP levels were measured as described under "Materials and methods". Data represent means \pm standard error of the mean of at least three independent experiments. (TIFF $170 \mathrm{~kb}$ )

Additional file 2: Figure S2. Permanent transduction of shRNA for protein kinase (PKA) dramatically decreases PKA protein expression in the Raw 264.7 cell line, as determined by western blotting. (TIFF 268 kb)
} 


\section{Abbreviations}

$A_{2 A} R$ : adenosine $A 2 A$ receptor; $A_{2 B} R$ : adenosine $A 2 B$ receptor; $A N O V A$ : analysis of variance; $B C A$ : bicinchoninic acid; CAMP: cyclic adenosine monophosphalphate; CREB: CAMP responsive element binding protein; ELISA: enzyme-linked immunosorbent assay; EPAC1/2: Exchange protein directly activated by CAMP; H\&E: hematoxylin and eosin; IL: interleukin; LPS: lipopolysaccharide; MTX: methtrexate; PBS: phosphate-buffered saline; PDE4: phosphodiesterase 4; PKA: protein kinase A; shRNA: short hairpin RNA; TNFa: tumor necrosis factor alpha.

\section{Authors' contributions}

MPA performed the in vivo and in vitro experiments, interpreted the data and drafted the manuscript. MCM provided technical expertise, helped with experiments and reviewed the manuscript. AM performed in vitro experiments, helped with data interpretation, manuscript writing and statistical analysis and reviewed the manuscript. TW helped with the in vivo experiments, assisted with statistical analysis and reviewed the manuscript. PHS helped plan the experiments, interpreted the data and revised the manuscript. BC conceived of the study, supervised the project, planned the experiments, analyzed the data and revised the manuscript. All authors read and approved the manuscript.

\section{Competing interests}

$A M$ and $B N C$ have filed a patent on use of adenosine $A_{2 A} R$ agonists to prevent prosthesis loosening (Patent number 8183225). AM and BNC have filled a patent on use of anti-netrin-1 antibodies for the treatment of bone disease (pending). PHS is an employee of Celgene Corporation. MP-A and MCM do not have any disclosures. BNC holds patents numbers 5,932,558; $6,020,321 ; 6,555,545 ; 7,795,427$; adenosine $A_{1} R$ and $A_{2 B} R$ antagonists to treat fatty liver (pending); adenosine $A_{2 A} R$ agonists to prevent prosthesis loosening (pending). BNC is a consultant for Bristol-Myers Squibb, Novartis, CanFite Biopharmaceuticals, Cypress Laboratories, Regeneron (Westat, DSMB), Endocyte, Protalex, Allos, Inc., Savient, Gismo Therapeutics, Antares Pharmaceutical, Medivector, King Pharmaceutical, Celizome, Tap Pharmaceuticals, Prometheus Laboratories, Sepracor, Amgen, Combinatorx, Kyowa Hakka, Hoffman-LaRoche and Avidimer Therapeutics. BNC has stock in CanFite Biopharmaceuticals. There are no other non-financial conflicts on the part of any of the authors.

\section{Acknowledgements}

This work was supported by grants from Celgene and the National Institutes of Health (AR56672 and AR54897), NYU-HHC (Health and Hospitals Corporation) Clinical and Translational Science Institute (UL1TR000038), the Laura and Isaac Perlmutter Cancer Center the Cancer Center Support Grant (P30CA016087) and NIH/ORIP S100D01058.

\section{Author details}

'Department of Medicine, New York University School of Medicine, 550 First Ave., New York, NY 10016, USA. ²Departament de Farmacologia, Facultat de Farmàcia, Universitat de València, 46100 Burjassot, Spain. ${ }^{3}$ Department of Translational Development, Celgene Corporation, Summit NJ, USA. ${ }^{4}$ Division of Translational Medicine, Department of Medicine, New York University School of Medicine, 550 First Avenue, MSB251, New York, NY 10016, USA.

Received: 3 March 2015 Accepted: 1 September 2015 Published online: 15 September 2015

\section{References}

1. Tasken $\mathrm{K}$, Aandahl EM. Localized effects of CAMP mediated by distinct routes of protein kinase A. Physiol Rev. 2004;84:137-67.

2. Kumar N, Goldminz AM, Kim N, Gottlieb AB. Phosphodiesterase 4-targeted treatments for autoimmune diseases. BMC Med. 2013:11:96.

3. Henney CS, Lichtenstein LM. The role of cyclic AMP in the cytolytic activity of Iymphocytes. J Immunol. 1971;107:610-2.

4. Jin SL, Ding SL, Lin SC. Phosphodiesterase 4 and its inhibitors in inflammatory diseases. Chang Gung Med J. 2012;35:197-210.

5. Essayan DM. Cyclic nucleotide phosphodiesterase (PDE) inhibitors and immunomodulation. Biochem Pharmacol. 1999:57:965-73.

6. Giembycz MA, Corrigan CJ, Seybold J, Newton R, Barnes PJ. Identification of cyclic AMP phosphodiesterases 3, 4 and 7 in human CD4+ and CD8+ T-lymphocytes: role in regulating proliferation and the biosynthesis of interleukin-2. Br J Pharmacol. 1996;118:1945-58.
7. Hidi R, Timmermans S, Liu E, Schudt C, Dent G, Holgate ST, et al Phosphodiesterase and cyclic adenosine monophosphate-dependent inhibition of T-lymphocyte chemotaxis. Eur Respir J. 2000;15:342-9.

8. Manning CD, Burman M, Christensen SB, Cieslinski LB, Essayan DM, Grous M, et al. Suppression of human inflammatory cell function by subtype-selective PDE4 inhibitors correlates with inhibition of PDE4A and PDE4B. Br J Pharmacol. 1999;128:1393-8

9. $\quad$ Spina D. PDE4 inhibitors: current status. Br J Pharmacol. 2008;155:308-15.

10. Giembycz MA. Phosphodiesterase 4 inhibitors and the treatment of asthma: where are we now and where do we go from here? Drugs. 2000;59:193-212

11. Dyke HJ, Montana JG. Update on the therapeutic potential of PDE4 inhibitors. Expert Opin Investig Drugs. 2002;11:1-13.

12. Dietsch GN, Dipalma CR, Eyre RJ, Pham TQ, Poole KM, Pefaur NB, et al. Characterization of the inflammatory response to a highly selective PDE4 inhibitor in the rat and the identification of biomarkers that correlate with toxicity. Toxicol Pathol. 2006;34:39-51.

13. Niu M, Dong F, Tang S, Fida G, Qin J, Qiu J, et al. Pharmacophore modeling and virtual screening for the discovery of new type 4 CAMP phosphodiesterase (PDE4) inhibitors. PLoS One. 2013;8:e82360.

14. Man HW, Schafer P, Wong LM, Patterson RT, Corral LG, Raymon H, et al. Discovery of (S)-N-[2-[1-(3-ethoxy-4-methoxyphenyl)-2methanesulfonylethyl]-1,3-dioxo-2,3-dihy dro-1H-isoindol-4-yl] acetamide (apremilast), a potent and orally active phosphodiesterase 4 and tumor necrosis factor-alpha inhibitor. J Med Chem. 2009;52:1522-4.

15. Schafer PH, Parton A, Capone L, Cedzik D, Brady H, Evans JF, et al. Apremilast is a selective PDE4 inhibitor with regulatory effects on innate immunity. Cell Signal. 2014;26:2016-29.

16. Schafer PH, Parton A, Gandhi AK, Capone L, Adams M, Wu L, et al. Apremilast, a CAMP phosphodiesterase-4 inhibitor, demonstrates anti-inflammatory activity in vitro and in a model of psoriasis. Br J Pharmacol. 2010;159:842-55.

17. Montesinos MC, Takedachi M, Thompson LF, Wilder TF, Fernandez $\mathrm{P}$, Cronstein BN. The antiinflammatory mechanism of methotrexate depends on extracellular conversion of adenine nucleotides to adenosine by ecto-5'-nucleotidase: Findings in a study of ecto-5'-nucleotidase gene-deficient mice. Arthritis Rheum. 2007;56:1440-5.

18. Momtazi M, Kwan P, Ding J, Anderson CC, Honardoust D, Goekjian S, et al. A nude mouse model of hypertrophic scar shows morphologic and histologic characteristics of human hypertrophic scar. Wound Repair Regen. 2013:21:77-87.

19. Mediero A, Perez-Aso M, Cronstein BN. Activation of EPAC1/2 is essential for osteoclast formation by modulating NFkappaB nuclear translocation and actin cytoskeleton rearrangements. FASEB J. 2014;28:4901-13.

20. McCann FE, Palfreeman AC, Andrews M, Perocheau DP, Inglis JJ, Schafer P, et al. Apremilast, a novel PDE4 inhibitor, inhibits spontaneous production of tumour necrosis factor-alpha from human rheumatoid synovial cells and ameliorates experimental arthritis. Arthritis Res Ther. 2010;12:R107.

21. Hasko G, Cronstein B. Regulation of inflammation by adenosine. Front Immunol. 2013;4:85.

22. Pessler F, Mayer CT, Jung SM, Behrens EM, Dai L, Menetski JP, et al. Identification of novel monosodium urate crystal regulated mRNAs by transcript profiling of dissected murine air pouch membranes. Arthritis Res Ther. 2008;10:R64.

23. Wen AY, Sakamoto KM, Miller LS. The role of the transcription factor CREB in immune function. J Immunol. 2010;185:6413-9.

24. Schett G, Sloan VS, Stevens RM, Schafer P. Apremilast: a novel PDE4 inhibitor in the treatment of autoimmune and inflammatory diseases. Ther Adv Musculoskelet Dis. 2010;2:271-8.

25. Nemeth ZH, Lutz CS, Csoka B, Deitch EA, Leibovich SJ, Gause WC, et al. Adenosine Augments IL-10 Production by Macrophages through an A2B Receptor-Mediated Posttranscriptional Mechanism. J Immunol. 2005;175:8260-70.

26. Hasko G, Pacher P, Deitch EA, Vizi ES. Shaping of monocyte and macrophage function by adenosine receptors. Pharmacol Ther. 2007;113:264-75.

27. Kara FM, Chitu V, Sloane J, Axelrod M, Fredholm BB, Stanley ER, et al. Adenosine $\mathrm{A} 1$ receptors (A1Rs) play a critical role in osteoclast formation and function. FASEB J. 2010;24:2325-33.

28. Pinhal-Enfield G, Ramanathan M, Hasko G, Vogel SN, Salzman AL, Boons GJ, et al. An angiogenic switch in macrophages involving synergy between Toll-like receptors 2, 4, 7, and 9 and adenosine $A(2 A)$ receptors. Am J Pathol. 2003;163:711-21. 
29. Cronstein BN, Eberle MA, Gruber HE, Levin RI. Methotrexate inhibits neutrophil function by stimulating adenosine release from connective tissue cells. Proc Natl Acad Sci U S A. 1991;88:2441-5.

30. Cheng X, Ji Z, Tsalkova T, Mei F. Epac and PKA: a tale of two intracellular CAMP receptors. Acta Biochim Biophys Sin. 2008:40:651-62.

31. Cooper DM, Tabbasum VG. Adenylate cyclase-centred microdomains. Biochem J. 2014;462:199-213.

32. Perez-Aso M, Mediero A, Cronstein BN. Adenosine A2A receptor (A2AR) is a fine-tune regulator of the collagen1:collagen3 balance. Purinergic signalling. 2013:9:573-83.

33. Gottlieb AB, Strober B, Krueger JG, Rohane P, Zeldis JB, Hu CC, et al. An open-label, single-arm pilot study in patients with severe plaque-type psoriasis treated with an oral anti-inflammatory agent, apremilast. Curr Med Res Opin. 2008:24:1529-38.

34. Tokuda H, Hirade K, Wang X, Oiso Y, Kozawa O. Involvement of SAPK/JNK in basic fibroblast growth factor-induced vascular endothelial growth factor release in osteoblasts. J Endocrinol. 2003;177:101-7.

35. Muller GW, Shire MG, Wong LM, Corral LG, Patterson RT, Chen Y, et al. Thalidomide analogs and PDE4 inhibition. Bioorg Med Chem Lett. 1998;8:2669-74.

36. Borchers AT, Keen CL, Cheema GS, Gershwin ME. The use of methotrexate in rheumatoid arthritis. Semin Arthritis Rheum. 2004;34:465-83.

37. Schulte G, Fredholm BB. Signalling from adenosine receptors to mitogenactivated protein kinases. Cell Signal. 2003;15:813-27.

38. Barrera P, Haagsma CJ, Boerbooms AM, Van Riel PL, Borm GF, Van de Putte LB, et al. Effect of methotrexate alone or in combination with sulphasalazine on the production and circulating concentrations of cytokines and their antagonists. Longitudinal evaluation in patients with rheumatoid arthritis Br J Rheumatol. 1995:34:747-55.

39. Spadaro A, Taccari E, Riccieri V, Sensi F, Sili Scavalli A, Zoppini A. Relationship of soluble interleukin-2-receptor and interleukin-6 with class-specific rheumatoid factors during low-dose methotrexate treatment in rheumatoid arthritis. Rev Rhum Engl Ed. 1997;64:89-94.

40. Gerards AH, de Lathouder S, de Groot ER, Dijkmans BA, Aarden LA Inhibition of cytokine production by methotrexate. Studies in healthy volunteers and patients with rheumatoid arthritis. Rheumatology. 2003;42:1189-96.

41. Sung JY, Hong JH, Kang HS, Choi I, Lim SD, Lee JK, et al. Methotrexate suppresses the interleukin- 6 induced generation of reactive oxygen species in the synoviocytes of rheumatoid arthritis. Immunopharmacology. 2000;47:35-44

42. Olsen NJ, Spurlock 3rd CF, Aune TM. Methotrexate induces production of IL-1 and IL-6 in the monocytic cell line U937. Arthritis Res Ther. 2014;16:R17.

43. Schafer $P$, Chen P, Fang L, Wang A, Chopra R: Apremilast, an oral phosphodiesterase 4 inhibitor, in patients with psoriatic arthritis: pharmacodynamic results of a phase 3 , randomized controlled trial. Annual European Congress of Rheumatology 2014:SAT0402.

44. Rich TC, Xin W, Mehats C, Hassell KA, Piggott LA, Le X, et al. Cellular mechanisms underlying prostaglandin-induced transient CAMP signals near the plasma membrane of HEK-293 cells. Am J Physiol Cell Physiol. 2007;292:C319-31.

45. McConnachie G, Langeberg LK, Scott JD. AKAP signaling complexes: getting to the heart of the matter. Trends Mol Med. 2006:12:317-23.

46. Zaccolo M, Movsesian MA. CAMP and CGMP signaling cross-talk: role of phosphodiesterases and implications for cardiac pathophysiology. Circ Res. 2007;100:1569-78

47. Fischmeister R, Castro LR, Abi-Gerges A, Rochais F, Jurevicius J, Leroy J, et al. Compartmentation of cyclic nucleotide signaling in the heart: the role of cyclic nucleotide phosphodiesterases. Circ Res. 2006;99:816-28.

48. Georg S, Hu A, Stevens R. Oral Apremilast Is Effective with and without Concomitant Methotrexate Therapy in the Treatment of Subjects with Active Psoriatic Arthritis [abstract]. Arthritis Rheum. 2011;63:10.

49. Kavanaugh A, Mease PJ, Gomez-Reino JJ, Adebajo AO, Wollenhaupt J, Gladman DD, et al. Treatment of psoriatic arthritis in a phase 3 randomised, placebo-controlled trial with apremilast, an oral phosphodiesterase 4 inhibitor. Ann Rheum Dis. 2014;73:1020-6.

50. Eigler A, Siegmund B, Emmerich U, Baumann KH, Hartmann G, Endres S. Anti-inflammatory activities of CAMP-elevating agents: enhancement of IL-10 synthesis and concurrent suppression of TNF production. J Leukoc Biol. 1998:63:101-7.
51. de Rooij J, Zwartkruis FJ, Verheijen MH, Cool RH, Nijman SM, Wittinghofer A, et al. Epac is a Rap1 guanine-nucleotide-exchange factor directly activated by cyclic AMP. Nature. 1998;396:474-7.

52. Bryn T, Mahic M, Enserink JM, Schwede F, Aandahl EM, Tasken K. The cyclic AMP-Epac1-Rap1 pathway is dissociated from regulation of effector functions in monocytes but acquires immunoregulatory function in mature macrophages. J Immunol. 2006;176:7361-70.

53. Hertz AL, Bender AT, Smith KC, Gilchrist M, Amieux PS, Aderem A, et al Elevated cyclic AMP and PDE4 inhibition induce chemokine expression in human monocyte-derived macrophages. Proc Natl Acad Sci U S A. 2009;106:21978-83.

\section{Submit your next manuscript to BioMed Central and take full advantage of:}

- Convenient online submission

- Thorough peer review

- No space constraints or color figure charges

- Immediate publication on acceptance

- Inclusion in PubMed, CAS, Scopus and Google Scholar

- Research which is freely available for redistribution

Submit your manuscript at www.biomedcentral.com/submit
C) Biomed Central 